\title{
Marked elevation of troponin I without wall motion abnormality in a patient with myocarditis: Cardiac enzymes may not predict the outcome in myocarditis
}

\author{
Abdullah Ozkok ${ }^{1}$, Ayhan Atakan², Goksel Acar ${ }^{3}$, Riza Atas$^{1}$, Omer Kaya ${ }^{1}$, Bahtiyar Toz ${ }^{1}$, \\ Murat Kose ${ }^{1}$, Timur Selcuk Akpinar ${ }^{1}$, Fatih Tufan ${ }^{1}$, Huseyin Oflaz ${ }^{2}$ \\ ${ }^{1}$ Department of Internal Medicine, Istanbul Faculty of Medicine, Istanbul University, Istanbul, Turkey \\ ${ }^{2}$ Department of Cardiology, Istanbul Faculty of Medicine, Istanbul University, Istanbul, Turkey \\ ${ }^{3}$ Department of Cardiology, Kartal Kosuyolu Heart and Research Hospital, Istanbul, Turkey \\ Email: abdullahozkok@yahoo.com
}

Received 4 April 2013; revised 4 May 2013; accepted 12 May 2013

Copyright (C 2013 Abdullah Ozkok et al. This is an open access article distributed under the Creative Commons Attribution License, which permits unrestricted use, distribution, and reproduction in any medium, provided the original work is properly cited.

\begin{abstract}
A seventeen-year-old male presented with severe substernal chest pain after an episode of upper respiratory tract infection. On clinical grounds, a diagnosis of myocarditis was established. He had a peak troponin I level as high as $40.4 \mathrm{ng} / \mathrm{dl}$ but interestingly with no abnormal wall motion and normal ejection fraction in echocardiography. Coronary artery disease was excluded with normal coronary angiography. Diagnosis of myocarditis was confirmed with cardiac MRI. After one month, patient had no complaint and ejection fraction were still normal. Our case emphasizes that the troponin levels predict neither the early nor the late outcome of the left ventricular functions in myocarditis, therefore serum troponin I may not be helpful in determining the prognosis of patients with myocarditis.
\end{abstract}

Keywords: Myocarditis; Troponin; Prognosis; Cardiac Enzymes

\section{INTRODUCTION}

Acute myocarditis is defined as an inflammation of the myocardium caused by a variety of factors including infection, systemic diseases, drugs and toxins. Troponin I is a sensitive and highly specific serum marker for cardiac injury including acute myocarditis. Herein we report a case of acute myocarditis with one of the highest peak serum Troponin I levels in the literature and discuss whether this cardiac biomarker may predict the outcome of left ventricular functions.

\section{CASE PRESENTATION}

A 17-year-old previously healthy male was presented with severe substernal chest pain of sudden onset for 2 hours that radiates to the left arm and oppressive in character. He had upper respiratory system complaints a week ago. He had 4 pockets/year smoking history and had no family or relative member who had myocardial infarction or sudden death in young ages. He denied the use of alcohol or recreational drugs. He was not febrile. His blood pressure was 120/80 mmHg and pulse was 84 beats/min. Cardiovascular and other systemic physical examination was normal. His electrocardiography showed $1 \mathrm{~mm}$ ST elevations in leads II, aVL, V5, V6 and $1 \mathrm{~mm}$ ST depression in leads V1 and V2 (Figure 1). Complete blood counts, electrolytes, LDH and creatinine levels were normal but AST: $60 \mathrm{U} / \mathrm{L}$, CK: $589 \mathrm{U} / \mathrm{L}$, CK-MB: $65 \mathrm{U} / \mathrm{L}$ and Troponin I: $20.3 \mathrm{ng} / \mathrm{dl}$ were detected. Echocardiogram revealed normal chamber size, normal systolic functions and ejection fraction (EF: 65\%) and minimal tricuspid regurgitation; pulmonary artery pressure was $30 \mathrm{mmHg}$. No wall motion abnormality was detected. On clinical grounds, the diagnosis of acute myocarditis was established.

The patient's follow-up was continued in the coronary intensive care unit. Coronary angiography revealed normal coronaries ruling out acute coronary syndrome. Peak troponin I level was $40.4 \mathrm{ng} / \mathrm{dl}$, peak CK: $859 \mathrm{U} / \mathrm{L}$, CK-MB: 80 U/L, LDH: 694 U/L, AST: 91 U/L. C-reactive protein (CRP) was elevated $(2.68 \mathrm{mg} / \mathrm{dl}$ ) (referance interval: 0 - 0.8). Within a few days of supportive treatment, chest pain resolved and elevation of these values subsided. At follow-up no ECG change was observed.

To find the etiology of myocarditis, viral serology was drawn for CMV, Toxoplasma, Rubella, Parvovirus and HSV and all were negative. ANA, Anti-DNA were negative and ASO titer was in normal range. One month later 


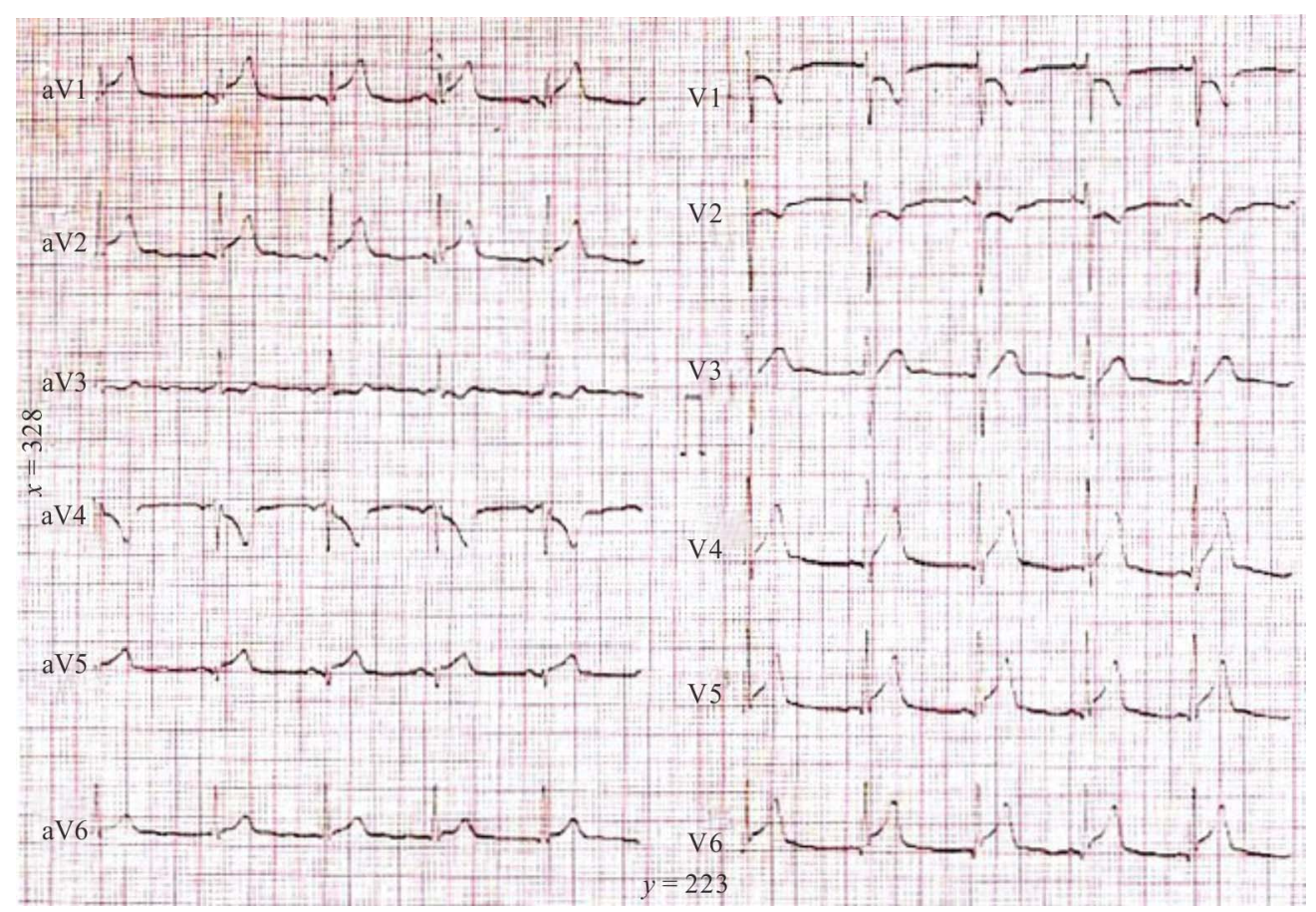

Figure 1. Electrocardiography showing $1 \mathrm{~mm}$ ST elevations in leads II, aVL, V5, V6 and $1 \mathrm{~mm}$ ST depression in leads V1 and V2.

cardiac echocardiography was totally normal with normal wall motions and ejection fraction. Cardiac enzymes (troponin I and CK-MB) were normal and the patient's NYHA functional class was 1 . In exercise myocardial perfusion SPECT with TL-201, during stress, hypoperfusion was detected in anteroseptal wall and hypoperfusion of this region disappeared during resting state. Cardiac MRI was also performed and showed myocardial edema in the anteroseptal wall confirming the diagnosis of myocarditis.

\section{DISCUSSION}

Troponin I, which regulates the calcium-mediated interaction between actin and myosin, is a sensitive and highly specific serum marker for cardiac injury [1]. Troponin elevations indicate the presence but not the mechanism of myocardial injury and myocardial damage can occur from reversible or irreversible non-ischemic myocardial injury such as acute myocarditis, acute pericarditis, acute or severe heart failure and sepsis [2]. The changes in myocyte membrane related to reversible injury cause the release of cardiac troponin I from the free cytosolic pool of the myocytes, whereas in the case of myocardial necrosis the source of troponin release is from the structural damage to the myocytes [3].

To our knowledge, Troponin I level in our case is the one of the highest Troponin I elevation associated with acute myocarditis (Peak level: $40.4 \mathrm{ng} / \mathrm{ml}$ ). Interestingly, there was no wall motion abnormality and ejection fraction was normal in echocardiographies at presentation and 1 month later. This underlines the fact that there may be no correlation between the peak values of cardiac enzymes and the initial or follow-up left ventricular ejection fraction.

Peak troponin $\mathrm{T}$ is well-known to be a prognostic indicator and predictor of infarct size in patients with acute myocardial infarction [4]. However, in the review of the literature, increased troponin levels do not seem to predict the outcome of left ventricular outcome in myocarditis [5-8]. In the study by Kobayshi et al., no evidence of myocardial dysfunction was observed in 12 myocarditis patients with elevated cardiac enzymes in the short term [7]. Similarly, in the study by Ammann et al., measurement of troponin I, CK and myoglobin did not predict early and late outcome of the left ventricular EF [8]. Furthermore, serum troponin I levels did not correlate with the histological severity of myocarditis $[9,10]$. The frequency of heart failure symptoms, NYHA functional class, ejection fraction, arrhythmia was equal in patients with and without troponin increase [11].

In conclusion, our case emphasizes that the measurement of cardiac enzymes predicts neither the early nor the late outcome of the left ventricular functions in myocarditis. The extent of myocardial damage seems to be independent of the initial measurement of myocardial enzyme activity and therefore these laboratory parameters may not be helpful in determining the prognosis of pa- 
tients with myocarditis.

\section{REFERENCES}

[1] Adams, J.E., Bodor, G.S., Davila-Roman, V.G., Delmez, J.A., Apple, F.S., Ladenson, J.H., et al. (1993) Cardiac troponin I: A marker with high specificity for cardiac injury. Circulation, 88, 101-106. doi:10.1161/01.CIR.88.1.101

[2] Roongsritong, C., Warraich, I. and Bradley, C. (2004) Common causes of troponin elevations in the absence o acute myocardial infarction. Chest, 125, 1877-1884. doi:10.1378/chest.125.5.1877

[3] Muhammad, A., Baig, et al. (2006) Cardiac troponin I release in non-ischemic reversible myocardial injury from parvovirus B19 myocarditis. International Journal of Cardiology, 113, E109-E110.

[4] Hassan, A.K., Bergheanu, S.C., Hasan-Ali, H., Liem, S.S., van der Laarse, A., Wolterbeek, R., Atsma, D.E., Schalij, M.J. and Jukema, J.W. (2009) Usefulness of peak troponin-T to predict infarct size and long-term outcome in patients with first acute myocardial infarction after primary percutaneous coronary intervention. American Journal of Cardiology, 103, 779-784. doi:10.1016/j.amjcard.2008.11.031

[5] Imazio, M., Cecchi, E., Demichelis, B., Chinaglia, A., Ierna, S., Demarie, D., Ghisio, A., Pomari, F., Belli, R. and Trinchero, R. (2008) Myopericarditis versus viral or idiopathic acute pericarditis. Heart, 94, 498-501. doi:10.1136/hrt.2006.104067

[6] Imazio, M., Demichelis, B., Cecchi, E., Belli, R., Ghisio, A., Bobbio, M. and Trinchero, R. (2003) Cardiac troponin I in acute pericarditis. Journal of the American College of Cardiology, 42, 2144-2148.

doi:10.1016/j.jacc.2003.02.001

[7] Kobayashi, D., Aggarwal, S., Kheiwa, A. and Shah, N. (2012) Myopericarditis in children: Elevated troponin I level does not predict outcome. Pediatric Cardiology, 33, 1040-1045. doi:10.1007/s00246-012-0222-y

[8] Ammann, P., Naegeli, B., Schuiki, E., Straumann, E., Frielingsdorf, J., Rickli, H. and Bertel, O. (2003) Longterm outcome of acute myocarditis is independent of cardiac enzyme release. International Journal of Cardiology, 89, 217-222. doi:10.1016/S0167-5273(02)00478-3

[9] Smith, S.C., Ladenson, J.H., Mason, J.W. and Jaffe, A.S. (1996) Elevation of cardiac troponin I associated with myocarditis. Experimental and clinical correlates. Circulation, 95, 163-168. doi:10.1161/01.CIR.95.1.163

[10] Mason, J.W., O’Connell, J.B., Herskowitz, A., Rose, N.R., McManus, B.M., Billingham, M.E., et al. (1995) A clinical trial of immunosuppressive therapy for myocarditis. New England Journal of Medicine, 333, 269-275. doi:10.1056/NEJM199508033330501

[11] Feldman, A.M. and McNamara, D. (2000) Medical progress: myocarditisitis. New England Journal of Medicine, 343, 1388-1398. doi:10.1056/NEJM200011093431908

\section{LIST OF ABBREVATIONS}

ANA: anti-nuclear antibody

Anti-DNA: anti deoxy-ribonucleic acid

AST: aspartat transaminaz

CK: creatinine kinase

CK-MB: creatinine kinase-MB

CMV: cytomegalovirus

CRP: C-reactive protein

ECG: electrocardiography

EF: ejection fraction

HSV: herpes simplex virus

LDH: lactate dehydrogenase

NYHA: New York Heart Association

MRI: magnetic resonance imaging

SPECT: single-photon emission computed tomography 